\title{
Factors associated with increased milk production for automatic milking systems
}

\author{
Marlène Tremblay, ${ }^{1}{ }^{1}$ Justin P. Hess, ${ }^{*}$ Brock M. Christenson, ${ }^{*}$ Kolby K. Mclntyre, ${ }^{*}$ Ben Smink, $\dagger$ \\ Arjen J. van der Kamp,ł Lisanne G. de Jong,ł and Dörte Döpfer* \\ ${ }^{*}$ Departments of Medical Sciences, Section of Food Animal Production Medicine, School of Veterinary Medicine, University of Wisconsin, \\ 2015 Linden Drive, Madison 53706 \\ †Lely North America, 775 250th Avenue, Pella, IA 50219 \\ fLely International N.V., Cornelis van der Lelylaan 1, 3147 PB, Maassluis, the Netherlands
}

\begin{abstract}
Automatic milking systems (AMS) are increasingly popular throughout the world. Our objective was to analyze 635 North American dairy farms with AMS for (risk) factors associated with increased milk production per cow per day and milk production per robot per day. We used multivariable generalized mixed linear regressions, which identified several significant risk factors and interactions of risk factors associated with milk production. Free traffic was associated with increased production per cow and per robot per day compared with forced systems, and the presence of a single robot per pen was associated with decreased production per robot per day compared with pens using 2 robots. Retrofitted farms had significantly less production in the first 4 yr since installation compared with production after $4 \mathrm{yr}$ of installation. In contrast, newly built farms did not see a significant change in production over time since installation. Overall, retrofitted farms did not produce significantly more or less milk than newly constructed farms. Detailed knowledge of factors associated with increased production of AMS will help guide future recommendations to producers looking to transition to an AMS and maximize their production.
\end{abstract}

Key words: automatic milking system, traffic type, number of robots per pen, milk production, benchmark

\section{INTRODUCTION}

Automatic milking systems (AMS) are becoming increasingly popular throughout the world, especially in North America. A variety of recommendations have been made for AMS facility structure and management to maximize production, but few of these recommendations have been explored scientifically (as reviewed

Received July 21, 2015.

Accepted January 10, 2016.

${ }^{1}$ Corresponding author: mtremblay@wisc.edu by Jacobs and Siegford, 2012). As AMS are integrated into farms with larger herds, facility details such as the number of robots per pen and traffic type (i.e., how cows move among the AMS, lying stalls, and feeding area) become increasingly important as minor effects on milk production in the short term can have major economic implications in the long term.

In free traffic barns, each cow decides when to enter the AMS and can move freely among the AMS, lying stalls, and feeding area. Non-free traffic (i.e., forced) may vary in the level of guidance that is applied during movement, but always directs movement from the lying stalls to the AMS before allowing access to the feeding alley. In strictly forced traffic situations, a cow is always milked before entering the feeding area, whereas alternative arrangements use selection gates (i.e., guided, semi-forced, or select) to select only those cows that have exceeded their milking interval (Melin et al., 2006).

Current literature does not give a clear consensus as to the ideal traffic type for maximizing production. The few studies published examining the relationship between traffic type and milk yield were limited by sample size. Hermans et al. (2003) and Bach et al. (2009) did not find a significant difference in milk yield between different traffic types but were limited to 85 cows and 130 cows, respectively. Similarly, Munksgaard et al. (2011) demonstrated slightly greater production with free traffic barns, but this was not a significant finding potentially due to their limited sample size (70 cows). Gygax et al. (2007) collected data from 20 cows per farm on 4 free traffic type farms and 4 forced traffic type farms each with either Brown Swiss or Holstein cows, but found no significant difference between traffic types.

The effect of the number of robots per pen of cows has also never been investigated in AMS herds. It has been suggested that producers keep group sizes under 100 cows to ensure that all cows recognize each other (Grant and Albright, 2001); however, this value has not 
been formally evaluated in an AMS (Rodenburg, 2002). Although, no significant difference in milk production or behavior was found between group sizes of 6 or 12 cows (Telezhenko et al., 2012), no similar studies have examined larger groups.

To date, no large-scale data analyses are available comparing AMS facility structures that account for differences in management and specific environments (as reviewed by Jacobs and Siegford, 2012). The general aim of this study was to apply multivariable generalized mixed linear regression models to a data set from 635 North American dairy farms to identify risk factors and interaction terms significantly associated with milk production per cow per day and milk production per robot per day. Our hypothesis is that traffic type and the number of robots per pen are risk factors significantly associated with milk production per robot per day and per cow per day. Factors that significantly affect a herd's maximum production limit could be used to create benchmark comparison groups for producers in the future. Detailed knowledge about factors associated with increased production of AMS will help guide future recommendations to producers looking to transition to an AMS and maximize their production.

\section{MATERIALS AND METHODS}

We analyzed a data set collected from weekly observations collected over 4 yr (2011-2014) at 635 North American dairy farms with Lely Astronaut AMS (Lely Industries N.V., Maassluis, the Netherlands). These data included 71,213 weekly observations containing 21 AMS variables.

Of the 21 available variables, frequencies per category were computed for 9 categorical variables (Table 1). Traffic_Type was coded as "Free" or "Forced." "Forced" Traffic_Type included both strictly forced and guided traffic (i.e., semi-forced, select) as both use one-way traffic to guide the cows and they have the same effect on low-ranking cows (Thune et al., 2002; Melin et al., 2006). The Robots_per_Pen variable represented the number of robots per pen of cows. By default, this variable also represents the number of cows in a pen and the pen's physical dimensions. By design, each pen will have about 60 cows per robot. For example, Robots_per_Pen of "1" is designed with one robot in a pen of about 60 cows and Robots_per_Pen of "2" is designed with 2 robots in a pen of about 120 cows. Because the number of robots per pen was of more interest, the number of cows per pen was not included in the regression to avoid multicollinearity. The physical sizes of the farms' pens were not available for our analysis; however, the number of cows per robot was included to account for different ratios of cows to robots (Table 2). Observations that were labeled as having a Robots_per_Pen of "Unknown" or "0" were coded as missing values. Breed was categorized into 3 levels: "Holstein," "Jersey," and "Other." Breed "Other" represents all other breeds including Ayrshire, Brown Swiss, Guernsey, Red and White, Crosses, Mixed, and Unknown. Farm_Goal was either characterized by the "Quota" system for farms in Canada or "Max_Production" for farms in the United States that produce with the goal of maximum milk production. Grazing and organic farms ( $\mathrm{n}=3,768$ observations) were not included in the analysis because they had relatively few observations. Year_Since_Install represented the time from the installation of the robots to the time of each observation. Observations from farms utilizing robots for more than 4 yr were grouped together as " $>4$ yr." Robot_Free_Time is the average percentage of time per day the robot is unoccupied by a cow (this does not include the time per day the system is automatically cleaning the robot and the milk lines to the tank). Robot_Free_Time was broken down into 5 levels (Table 1). Record_Year was limited to 2011 to 2014. "Winter" was classified as December through February, "Spring" as March through May, "Summer" as June through August, and "Fall" as September through November.

The 12 numeric variables were summarized using descriptive statistics. The names of the numeric variables and their explanation are listed in Table 2. Observations with missing values were omitted. Observations that had fewer than 10 Cows_per_Robot or greater than 90 Cows_per_Robot were removed as outliers. The histogram of Average_DIM showed outliers beginning at $365 \mathrm{~d}$. After observations with an Average_DIM greater than 365 d were omitted, 54,065 observations remained representing 529 farms. The number of observations per categorical variable and their reference level are detailed in Table 1. Categorical levels were chosen as the level we were least interested in estimating an effect while still having a balanced amount of observations. The summary statistics of the numeric variables are shown in Table 2. All statistical analyses were performed in $\mathrm{R}$ version 3.0.1 (R Development Core Team, 2013).

All numeric variables were inspected for normality by creating histograms. Numeric variables were logtransformed when normality was not present upon visual inspection of the histogram or when the order of magnitude of the values was more than 3 logs higher than the other variables. All numeric variables were scaled and centered using the scale function in $\mathrm{R}$ (i.e., the mean of each variable was subtracted from all values per variable in the data set and then divided 
by the variable's standard deviation). The correlations between each pair of numeric variables were examined. A threshold of 0.7 was used to determine if a pair of variables was too highly correlated as this would lead to multicollinearity (Dormann et al., 2013). Based on this threshold criterion, the variables Milk_Production_per_Robot_per_Day and Cows_per_Robot are too highly correlated and therefore could not be used in the same regression model.

The number of observations differed among the combinations of independent variable levels (Table 1). These unequal numbers of observations also led to unequal variances among groups which render ANOVA methods unsuitable (Quinn and Keough, 2002). Therefore, we used multivariable generalized mixed linear regression models to generate 2 models (Quinn and Keough, 2002). Model 1 evaluated Milk_Production_per_Cow_ per_Day, whereas model 2 evaluated Milk_Production_per_Robot_per_Day. The variable Farm_ID was taken as the random effect to account for differences between farms and repeated measures between farms. For Milk_Production_per_Robot_per_Day regression, Cows_per_Robot was taken as an offset. To examine the effect of one predictor upon the other 2-way interactions were selected using forward selection and a t-value limit of 4 (Pasta, 2011). Backward elimination of simple main effects was performed based on an error level, $\alpha$, of 0.05 only if the variable was also not a confounder. Confounding effects were determined using the change-in-estimate method (Greenland, 1989). This method compares the model estimates before and after removal of the potential confounder variable from the model and any change in the estimates greater than $10 \%$ would signify a possible confounding effect. Goodness-of-fit measures were examined for each regression model using normality plots of residuals and log-likelihood, Akaike information criterion, Bayesian information criterion, and deviance measures. Interaction plots were produced using the R library package "effects" (Fox, 2003).

\section{RESULTS}

The first multivariable generalized linear mixed regression model incorporated 18 main effects and 20 of their 2-way interactions. Farm_ID was kept as a random effect and backward elimination removed Robots_per_Pen. Robots_per_Pen was not significant as a main effect $(P=0.75)$ and was not a confounder as the unadjusted model estimates on average only differed by $0.11 \%$ (SD 0.286) compared with the adjusted estimates. The regression results and equation for model 1 are shown in Table 3. The second multivariable generalized linear mixed regression model incorporated 18 main effects, 22 two-way interactions, Farm_ID as a random effect, and Cows_per_Robot as an offset. None of the variables were dropped during backward elimination because all factors were involved in significant main or interaction effects. The regression results and equation are shown in Table 4 . Ten of the interactions were shared by both models.

Table 1. The number of observations per categorical variable and their reference level

\begin{tabular}{|c|c|c|}
\hline Categorical variable $^{1}$ & Level & $\begin{array}{c}\text { Number of } \\
\text { observations }\end{array}$ \\
\hline \multirow[t]{2}{*}{ Traffic_Type } & Free & 50,268 \\
\hline & Forced $^{3}$ & 3,797 \\
\hline \multirow[t]{3}{*}{ Robots_per_Pen } & 1 & 30,946 \\
\hline & $2^{3}$ & 20,522 \\
\hline & $3+$ & 2,597 \\
\hline \multirow[t]{3}{*}{ Breed } & Holstein $^{3}$ & 49,124 \\
\hline & Jersey & 1,131 \\
\hline & Other & 3,810 \\
\hline \multirow[t]{2}{*}{ New_or_Retro } & $\mathrm{New}^{3}$ & 27,211 \\
\hline & Retro & 26,854 \\
\hline \multirow[t]{2}{*}{ Farm_Goal } & Quota-Canada $^{3}$ & 35,641 \\
\hline & Max_Production-USA & 18,424 \\
\hline \multirow[t]{5}{*}{ Years_Since_Install } & $0-1 \overline{\mathrm{yr}}$ & 18,115 \\
\hline & $1-2 \mathrm{yr}$ & 13,643 \\
\hline & $2-3$ yr & 8,449 \\
\hline & $3-4 \mathrm{yr}$ & 4,896 \\
\hline & $>4 \mathrm{yr}^{3}$ & 8,962 \\
\hline \multirow[t]{5}{*}{ Robot_Free_Time } & $0-5 \%$ & 11,694 \\
\hline & $5-10 \%$ & 11,413 \\
\hline & $10-15 \%^{3}$ & 7,601 \\
\hline & $15-20 \%$ & 6,282 \\
\hline & $>20 \%$ & 17,075 \\
\hline \multirow[t]{4}{*}{ Record_Year } & $2011^{3}$ & 4,680 \\
\hline & 2012 & 20,450 \\
\hline & 2013 & 16,079 \\
\hline & 2014 & 12,856 \\
\hline \multirow[t]{4}{*}{ Season } & Winter $^{3}$ & 12,318 \\
\hline & Spring & 14,530 \\
\hline & Summer & 15,991 \\
\hline & Fall & 11,226 \\
\hline
\end{tabular}

${ }^{1}$ Variable explanations: Traffic_Type $=$ how cows are allowed to move among areas of a barn. "Free" refers to a system where cows can decide when to enter the automatic milking system (AMS) and can move freely between the AMS, lying stalls, and the feeding area. "Forced" traffic type uses a one-way traffic system toward the AMS. Robots_per_Pen = number of AMS robots per pen; Breed = breed of cattle; New_or_Retro = newly built or retrofitted barn; Farm_ Goal = operate under the "Quota" system for farms in Canada or "Max_Production" for farms in the United States that produce with the goal of maximum milk production; Years_Since_Install = how recently (in years) the AMS was installed; Robot_Free_Time $=$ percent of time per day the robot is not occupied; Record_Year = year at the time of record; Season = "Winter" was classified as December through February, "Spring" as March through May, "Summer" as June through August, and "Fall" as September through November.

${ }^{2} 54,065$ total observations.

${ }^{3}$ Reference level. Reference levels were chosen as the level we were least interested in estimating an effect while still having a balanced amount of observations. 
Table 2. Explanation of numeric variables and descriptive statistics

\begin{tabular}{|c|c|c|c|}
\hline Numeric variable & Variable explanation & Mean $^{1}$ & SD \\
\hline Milk_Production_per_Robot_per_Day & Average kilograms of milk produced ${ }^{3}$ & $1,626.80$ & 396.99 \\
\hline Concentrates & $\begin{array}{l}\text { Average concentrate }(\mathrm{kg}) \text { consumed in robot or automatic feeder per } \\
100 \mathrm{~kg} \text { of milk yield }\end{array}$ & 15.86 & 5.38 \\
\hline Rest_Feed & $\begin{array}{l}\text { Average percentage of concentrates from the cow's allowance that was } \\
\text { not dispensed that day }{ }^{4}(\%)\end{array}$ & 7.73 & 7.38 \\
\hline Failures $^{3}$ & Average number of failed milkings ${ }^{3}$ & 5.49 & 3.46 \\
\hline Milkings $^{2}$ & Average number of successful milkings ${ }^{2}$ & 2.91 & 0.36 \\
\hline Milk_Speed & Average milk yield (kg) per milking time ( $\min )$ & 2.59 & 0.31 \\
\hline Boxtime $^{2}$ & Average minutes in the $\mathrm{AMS}^{2}$ (milking time and treatment time) & 6.84 & 0.70 \\
\hline Connection_Attempts ${ }^{3}$ & $\begin{array}{l}\text { Average number of failure where teats were detected, but a quarter } \\
\text { was unable to be connected }\end{array}$ & 1.41 & 0.23 \\
\hline
\end{tabular}

${ }^{1} 54,065$ total observations.

${ }^{2}$ Per cow per day. AMS = automated milking system.

${ }^{3}$ Per robot per day.

${ }^{4}$ Possible causes include that a cow was not visiting the robot often enough or she was not able to finish her meal while being milked.

The results of both models were very similar in terms of the direction of effects of the estimates and significance of the variables. Thus, results are described as their effects on Milk_Production to allude to both Milk_Production_per_Cow_per_Day and Milk_Production_per_Robot_per_Day unless specified. Most of these interaction effects are illustrated using Milk_Production_per_Cow_per_Day only. Most variables are also included in interactions. In these cases, the interpretation of interaction effects is considered more important than the main effect (Pasta, 2011). The model results are shown in the Tables 3 and 4 .

Traffic_Type "Free" was associated with greater Milk_Production (both models $P<0.001$ ) compared with "Forced" Traffic_Type. As a main effect, "Free" Traffic_Type produces on average $1.11 \mathrm{~kg}$ (CI: 0.791.43) more Milk_Production_per_Cow_per_Day and $67.2 \mathrm{~kg}$ (CI: 48.6-86.0) more Milk_Production_per_ Robot_per_Day than "Forced."

On average, Robots_per_Pen "2" (2 robots per 120 cows $)$ had greater $(P<0.001)$ Milk_Production_ per_Robot_per_Day compared with Robots_per_Pen "1" (one robot per 60 cows) as a main effect. Robots_per_Pen was included in 2 interactions (Table 4). The interaction Robots_per_Pen:Record_Year describes how Robots_per_Pen " $3+$ " and "2" had greater Milk_Production_per_Robot_per_Day compared with Robots_per_Pen "1" in Record_Year 2011 and 2012 (see nonoverlapping confidence intervals in Figure 1). Robots_per_Pen was also in an interaction with Milkings. The difference between Robots_per_Pen "1" and Robots_per_Pen "2" or " $3+$ " becomes larger as Milkings decreases below its average of 2.91 (SD: 0.36) Milkings (Table 4).
We found associations between increased Milkings, Milk_Speed, or Boxtime and increased Milk_Production (all $P<0.001$ ). The negative estimates for the interactions Milk_Speed:Boxtime and Milkings:Milk_ Speed in model 1 and Milkings:Milk_Speed and Milkings:Boxtime in model 2 indicate that the positive effect of the variables on Milk_Production decreases (smaller increase in production per unit change) as the value of the other variable in the interaction increases (all $P<0.001$ ). For example, the positive effect of Milk_Speed on Milk_Production decreases as Milkings increases. All 3 variables were also part of interactions with Connection_Attempts in both models that had negative estimates suggesting that the negative effect of Connection_Attempts on Milk_Production increases (all $P<0.001$ ) as Milkings, Milk_Speed, or Boxtime increase (Tables 3 and 4).

"Jersey" Breed was associated $(P<0.001)$ with less Milk_Production than "Holstein" Breed, whereas the "Other" Breed category was not significantly different from "Holstein" Breed as a main effect (model 1, $P=$ 0.31 ; model $2, P=0.08$ ). Although Breed was part of 2 interactions in both models, as a main effect "Jersey" produces on average $3.72 \mathrm{~kg}$ (CI: 3.29-4.14) less Milk_Production_per_Cow_per_Day and $216.71 \mathrm{~kg}$ (CI: 193.2-239.9) less Milk_Production_per_Robot_ per_Day compared with "Holstein" (milk production not energy corrected). Tables 3 and 4 illustrate the increase in difference in milk production between Holstein and Jersey breeds as the number of milkings increases. (model 1 and 2, $P<0.001$ ). When Refusals decreases, the difference in Milk_Production_per_Cow_per_Day between "Holstein" and "Jersey" increases $(P<0.001)$. When Connection_Attempts increases, the difference 
Table 3. Milk_Production_per_Cow_per_Day regression model results ${ }^{1,2}$

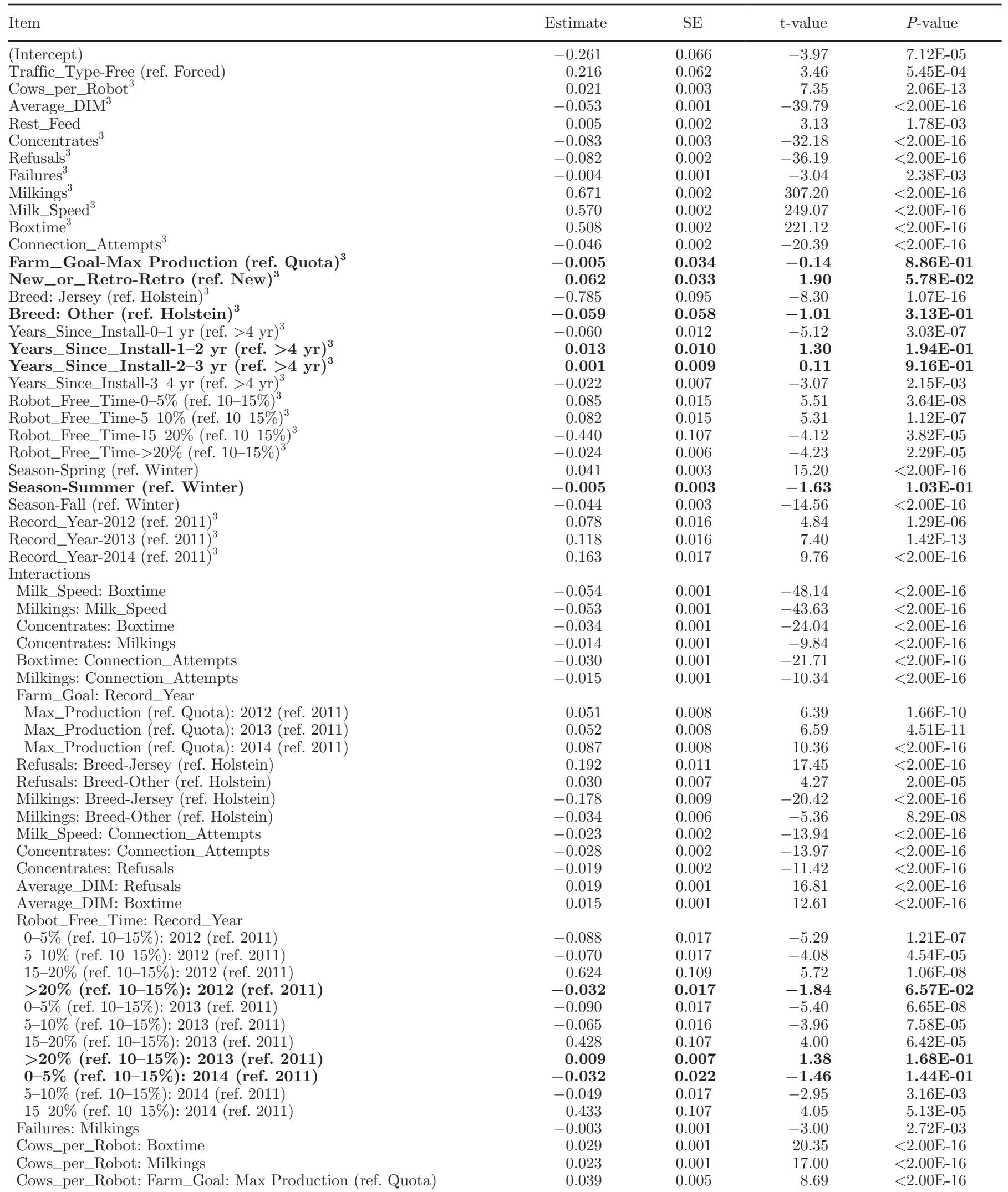


Table 3 (Continued). Milk_Production_per_Cow_per_Day regression model results ${ }^{1,2}$

\begin{tabular}{|c|c|c|c|c|}
\hline Item & Estimate & $\mathrm{SE}$ & t-value & $P$-value \\
\hline Retro (ref. New): 0-1 yr (ref. $>4$ yr) & -0.112 & 0.012 & -9.12 & $<2.00 \mathrm{E}-16$ \\
\hline Retro (ref. New): $3-4$ yr (ref. $>4$ yr) & -0.095 & 0.010 & -9.21 & $<2.00 \mathrm{E}-16$ \\
\hline
\end{tabular}

${ }^{1}$ Regression model equation: Milk_Production_per_Cow_per_Day $\sim$ Traffic_Type + Cows_per_Robot + Average_DIM + Rest_Feed + Concentrates + Refusals + Failures + Milkings + Milk_Speed + Boxtime + Connection_Attempts + Farm_Goal + New_of_Retro + Breed + Years_Since_Install + Robot_Free_Time + Season + Record_Year + (1|Farm_ID) + Milk_Speed: Boxtime + Milkings: Milk_Speed + Concentrates: Boxtime + Concentrates: Milkings + Boxtime: Connection_Attempts + Milkings: Connection_Attempts + Farm_Goal: Record_ Year + Refusals: Breed + Milkings: Breed + Milk_Speed: Connection_Attempts + Concentrates: Connection_Attempts + Concentrates: Refusals + Average_DIM: Refusals + Average_DIM: Boxtime + Robot_Free_Time: Record_Year + lognr_failures: Milkings + Cows_per_ Robot: Boxtime + Cows_per_Robot: Milkings + Cows_per_Robot: Farm_Goal + New_or_Retro: Year_Since_Install. Ref. $=$ reference level.

${ }^{2}$ Bold text indicates a nonsignificant effect $(P>0.05)$.

${ }^{3}$ The variable is also included in an interaction.

in Milk_Production_per_Robot_per_Day between "Holstein" and "Jersey" increases $(P<0.001)$.

Increases in Average_DIM, Failures, Concentrates, Refusals, and Connection_Attempts are all associated (all $P<0.01$ ) with decreased Milk_Production (all of the above variables are also included in interactions), whereas an increase in Rest_Feed is associated with increased Milk_Production (models 1 and $2, P<0.01$ ). The Farm_Goal:Record_Year interaction implies that "Max_Production" farms (United States) had more Milk_Production_per_Cow_per_Day compared with "Quota" farms (Canada) in all years except for 2011 (all $P<0.001$ ).

The interactions between Concentrates and 5 other numeric variables all have negative coefficients. Three out of the 5 interactions are included in both models as illustrated in Tables 3 and 4 . This means that the positive effects of Milkings, Milk_Speed, and Boxtime diminish as Concentrates increases (all $P<0.001$ ) and that the negative effects of Refusals and Connection Attempts increases (all $P<0.001$ ) as Concentrates increases (Figure 2).

Cows_per_Robot has a significant main effect $(P$ $<0.001)$ in the Milk_Production_per_Cow_per_Day model and is included in 3 interactions with Farm_Goal, Milkings, and Boxtime (all $P<0.001$ ). As Boxtime and Milkings decrease below $6.1 \mathrm{~min}$ or 2.4 milkings per cow per day, respectively, with other variables held at their mean, an increase in Cows_per_Robot will transition to having a negative effect on Milk_Production_per_Cow_per_Day (Figures 3 and 4).

Figure 5 illustrates the interaction New_or Retro:Years_Since_Install for Milk_Production_per_ Cow_per_Day, although the effect holds true for both models. The trend in Milk_Production_per_Cow_ per_Day estimates and confidence intervals for the "New" farms, demonstrates that Milk_Production does not change significantly between Years_Since_Install groups (depicted by overlapping confidence intervals in Figure 5). In contrast, for "Retro" farms, the righthanded side of Figure 5 shows that Milk_Production is significantly greater in "> $4 \mathrm{yr}$ " compared with all other categories of Years_Since_Install (depicted by nonoverlapping confidence intervals in Figure 5). On average, "Retro" farms do not produce significantly more or less than "New" farms, which is demonstrated by a nonsignificant $P$-value for the main effect $(P=$ 0.06; Table 3). The confidence intervals for Milk_Production between "New" and "Retro" farms overlap in all groups except for the "1-2 yr" group. After $2 \mathrm{yr}$, the Milk_Production for "New" or "Retro" farms are not significantly different (Figure 5).

The "Spring" Season had greater $(P<0.001)$ Milk_ Production compared with Season "Winter." Season "Fall" was associated with less $(P<0.001)$ Milk_Production compared with "Winter." The effect of "Summer" on Milk_Production_per_Cow_per_Day was not significantly different from "Winter" $(P=0.10)$. In the Milk_Production_per_Robot_per_Day model, Season was part of an interaction with Farm_Goal wherein "Max_Production" had decreased seasonal effects (all $P<0.001)$ compared with Farm_Goal "Quota." This causes "Summer" to have on average greater milk production than "Winter" in "Quota" farms (Canada) but less than "Winter" in "Max_Production" farms (United States).

Robot_Free_Time was significant in both models (all levels $P<0.001$ ) but depended highly on its interaction with Record_Year. There were relatively few observations with Robot_Free_Time greater than 15\% in Record_Year 2011 and 2012 (480 observations from 43 farms). All Robot_Free_Time categories for year 2013 and 2014 had more than 2,000 observations except the 2014 "0-5\%" category, which had 225 observations. Re- 
Table 4. Milk_Production_per_Robot_per_Day regression model results ${ }^{1,2}$

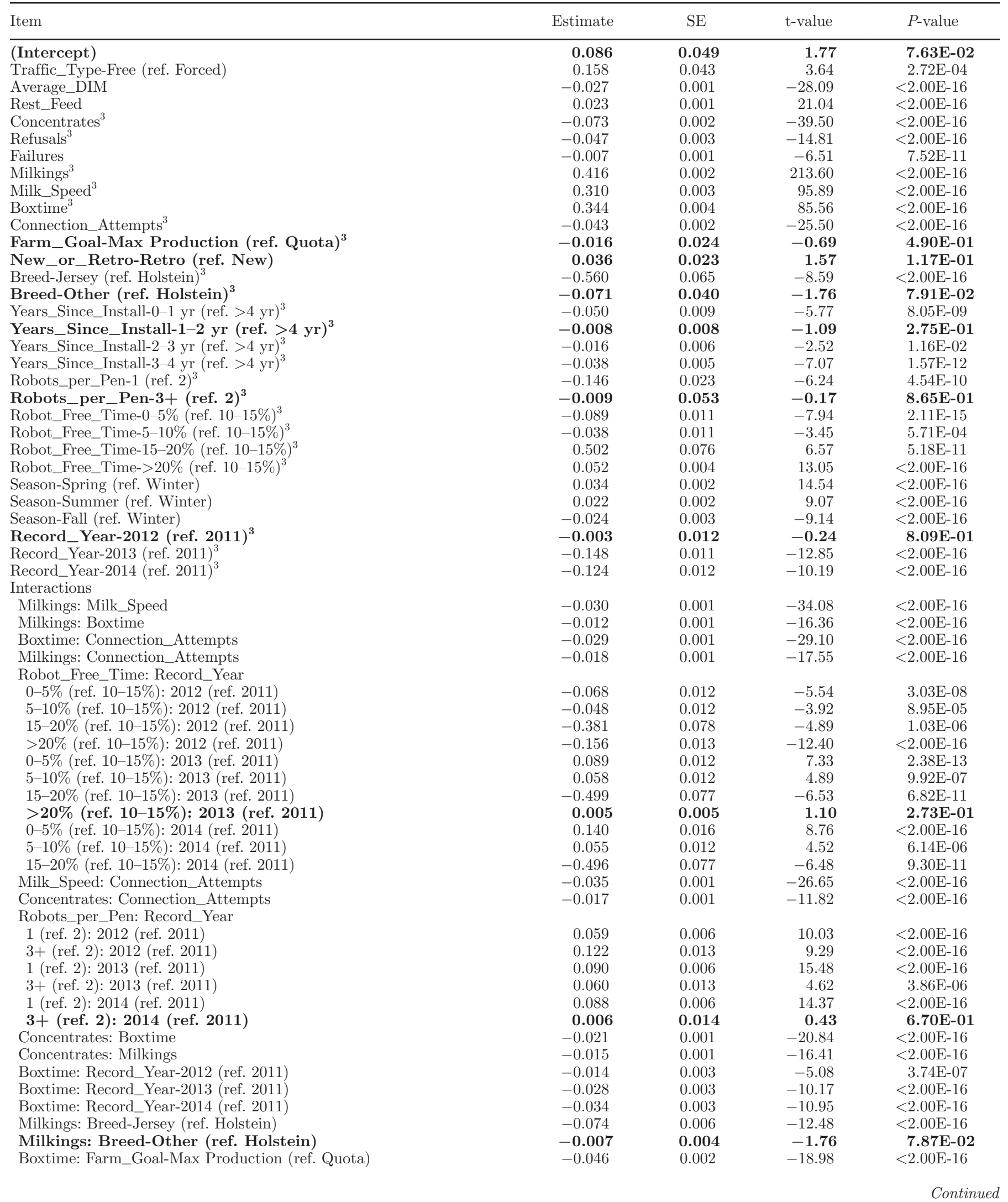


Table 4 (Continued). Milk_Production_per_Robot_per_Day regression model $\operatorname{results}^{1,2}$

\begin{tabular}{|c|c|c|c|c|}
\hline Item & Estimate & $\mathrm{SE}$ & t-value & $P$-value \\
\hline $0-1$ yr (ref. $>4$ yr): Retro (ref. New) & -0.088 & 0.009 & -9.82 & $<2.00 \mathrm{E}-16$ \\
\hline $1-2$ yr (ref. $>4$ yr): Retro (ref. New) & -0.113 & 0.009 & -13.05 & $<2.00 \mathrm{E}-16$ \\
\hline $3-4$ yr (ref. $>4$ yr): Retro (ref. New) & -0.051 & 0.008 & -6.74 & $1.59 \mathrm{E}-11$ \\
\hline Milkings: Robots_per_Pen-1 (ref. 2) & 0.028 & 0.002 & 13.27 & $<2.00 \mathrm{E}-16$ \\
\hline Milkings: Robots_per_Pen-3+ (ref. 2 ) & 0.030 & 0.005 & 5.55 & $2.80 \mathrm{E}-08$ \\
\hline Max Production (ref. Quota): Summer (ref. Winter) & -0.045 & 0.004 & -11.07 & $<2.00 \mathrm{E}-16$ \\
\hline Max Production (ref. Quota): Fall (ref. Winter) & -0.022 & 0.004 & -5.02 & $5.22 \mathrm{E}-07$ \\
\hline Refusals: Years_Since_Install- $0-1$ yr (ref. $>4$ yr) & 0.057 & 0.004 & 16.08 & $<2.00 \mathrm{E}-16$ \\
\hline Refusals: Years_Since_Install-1-2 yr (ref. $>4$ yr) & 0.030 & 0.004 & 8.30 & $1.04 \mathrm{E}-16$ \\
\hline Refusals: Years_Since_Install-2-3 yr (ref. $>4$ yr) & 0.032 & 0.004 & 8.63 & $<2.00 \mathrm{E}-16$ \\
\hline Refusals: Years_Since_Install-3-4 yr (ref. $>4$ yr) & 0.021 & 0.004 & 5.39 & $7.11 \mathrm{E}-08$ \\
\hline Milk_Speed: Years_Since_Install-0-1 yr (ref. $>4$ yr) & 0.042 & 0.004 & 11.85 & $<2.00 \mathrm{E}-16$ \\
\hline Concentrates: Milk_Speed & -0.012 & 0.001 & -10.77 & $<2.00 \mathrm{E}-16$ \\
\hline Connection_Attempts: Farm_Goal-Max Production (ref. Quota) & 0.045 & 0.004 & 10.68 & $<2.00 \mathrm{E}-16$ \\
\hline Boxtime: Years_Since_Install- $0-1$ yr (ref. $>4$ yr) & 0.037 & 0.003 & 10.73 & $<2.00 \mathrm{E}-16$ \\
\hline Boxtime: Years_Since_Install-1-2 yr (ref. $>4$ yr) & 0.031 & 0.003 & 8.81 & $<2.00 \mathrm{E}-16$ \\
\hline Boxtime: Years_Since_Install-2-3 yr (ref. $>4$ yr) & 0.022 & 0.004 & 6.24 & $4.40 \mathrm{E}-10$ \\
\hline Boxtime: Years_Since_Install-3-4 yr (ref. $>4$ yr) & 0.025 & 0.004 & 6.48 & $9.43 \mathrm{E}-11$ \\
\hline
\end{tabular}

${ }^{1}$ Regression model equation: Milk_Production_per_Robot_per_Day $\sim$ Traffic_Type + Cows_per_Robot + Average_DIM + Rest_Feed + Concentrates + Refusals + Failures + Milkings + Milk_Speed + Boxtime + Connection_Attempts + Farm_Goal + New_or_Retro + Breed + Years_Since_Install + Robots_per_Pen + Robot_Free_Time + Season + Record_Year + (1|Farm_ID) + Milkings: Milk_Speed + Milkings: Boxtime + Boxtime: Connection_Attempts + Milkings: Connection_Attempts + Robot_Free_Time: Record_Year + Milk_Speed: Connection_ Attempts + Concentrates: Connection_Attempts + Robots_per_Pen: Record_Year + Concentrates: Boxtime + Concentrates: Milkings + Boxtime: Record_Year + Milkings: Breed + Boxtime: Farm_Goal + New_or_Retro: Years_Since_Install + Milkings: Robots_per_Pen + Farm_ Goal:Season + Refusals: Years_Since_Install + Milk_Speed: Years_Since_Install + Breed: Connection_Attempts + Concentrates: Milk_Speed + Connection_Attempts: Farm_Goal + Boxtime: Years_Since_Install, offset $=$ Cows_per_Robot. Ref. = reference level.

${ }^{2}$ Bold text indicates a nonsignificant effect $(P>0.05)$.

${ }^{3}$ The variable is also included in an interaction.

cord_Year 2013 and 2014 did not have any significant differences in Milk_Production_per_Cow_per_Day by Robot_Free_Time category (non-overlapping confidence intervals). Significantly greater Milk_Production_per_Robot_per_Day is seen within the "> 20\%" category in 2013 and 2014 compared with the reference group "10-15\%" (Table 4).

\section{DISCUSSION}

Goal-oriented production processes such as milk production in dairy herds can benefit from predictive models that correctly incorporate the effects of multiple risk factors and interactions of such factors simultaneously. Interactions facilitate the understanding of diverse relationships among management factors and improve our understanding of different management styles. Often the modeling approaches reported in literature are limited to the analysis of selected interactions. In contrast, the approach reported here systematically mined through all possible interactions to determine the most meaningful ones. Multivariable generalized mixed linear regression models identified sources of variation in Milk_Production for a large number of farms utilizing AMS across North America. Despite a large diversity of environments and management styles, several associations were consistent.

We found that "Free" Traffic_Type was associated with greater Milk_Production than "Forced" Traffic_Type in model 1 and model 2. A possible explanation for this is that forced traffic decreases the total feed a cow consumes, the total amount of time eating, and the number of times a cow visits the feed bunk (Ketelaar-de Lauwere et al., 2000; Harms et al., 2002; Melin et al., 2007). These changes in feeding behavior could potentially lead to rumen acidosis (Bach et al., 2009). Hermans et al. (2003) and Rodenburg (2012) suggested that forced traffic might negatively affect the behavior of timid cows more than dominant cows and Thune et al. (2002) found longer waiting periods for the 
a)

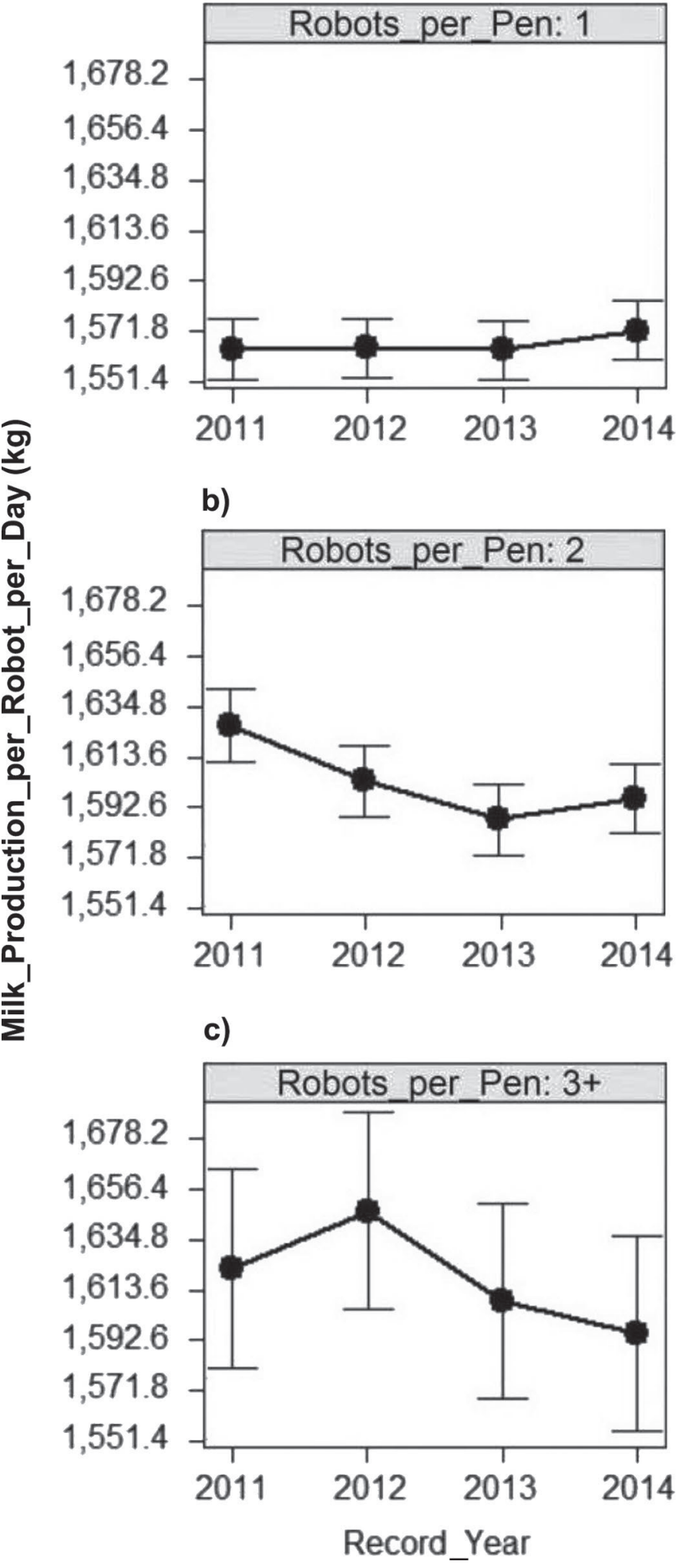

Figure 1. Interaction effects between predictor variables Robots_ per_Pen and Record_Year with Milk_Production_per_Robot_per_ Day as the response variable. Error bars indicate $95 \%$ confidence intervals. a)

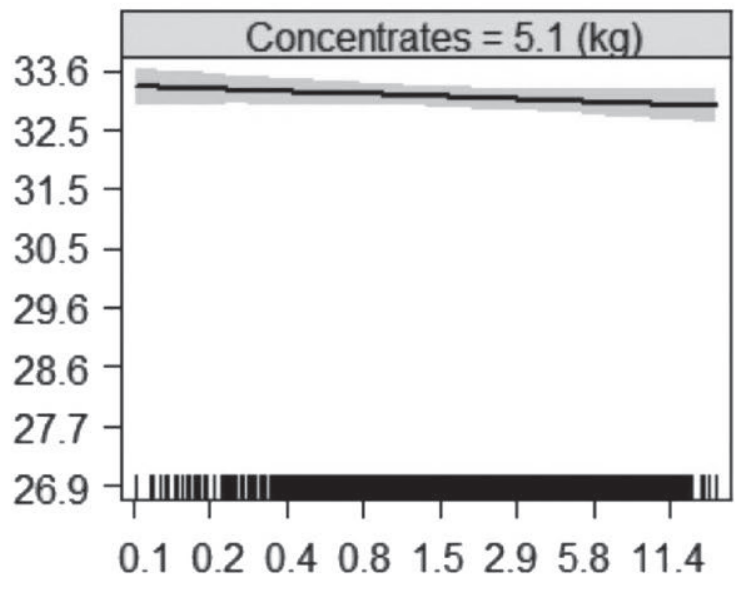

올

b)

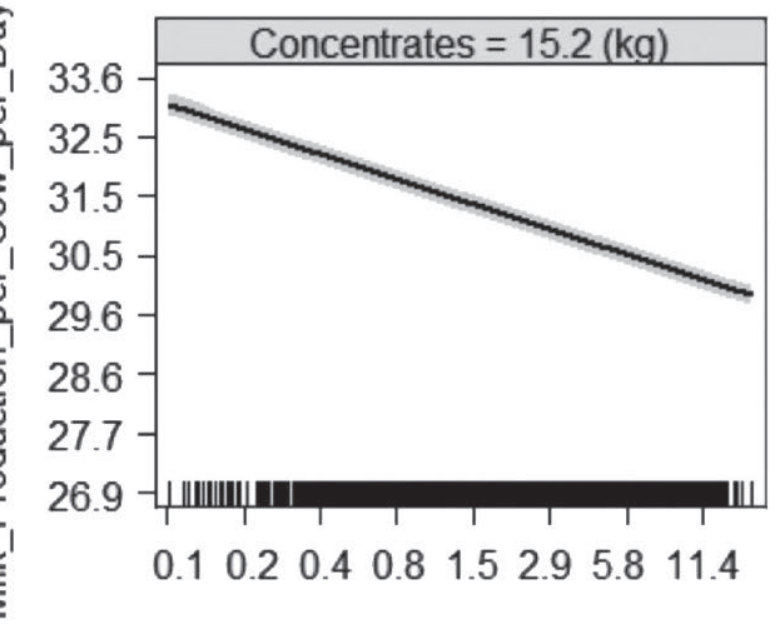

c)

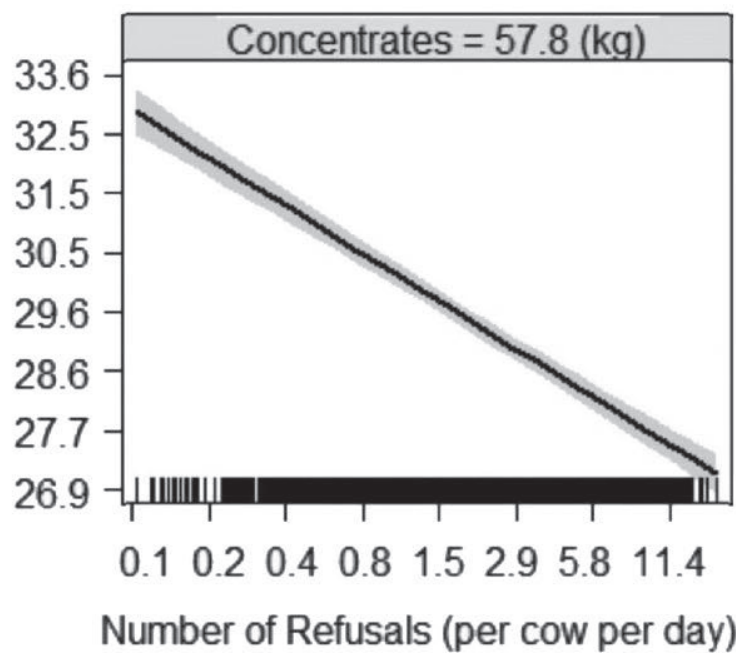

Figure 2. Interaction effects between predictor variables Concentrates and Refusals with Milk_Production_per_Cow_per_Day as the response variable. Tick marks on the $\mathrm{x}$-axis represent individual measurements. 
a)

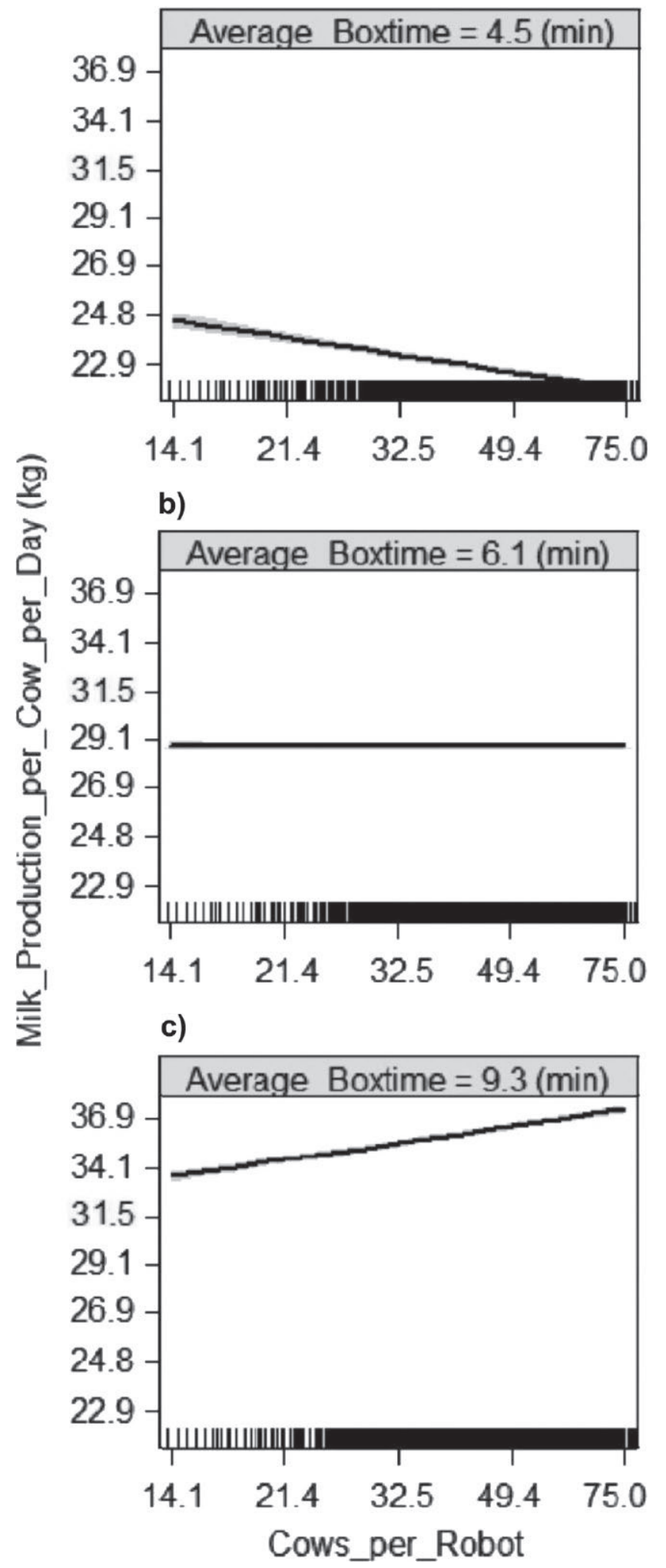

Figure 3. Interaction effects between predictor variables Cows_ per_Robot and Boxtime with Milk_Production_per_Cow_per_Day as the response variable. Tick marks on the $\mathrm{x}$-axis represent individual measurements. a)

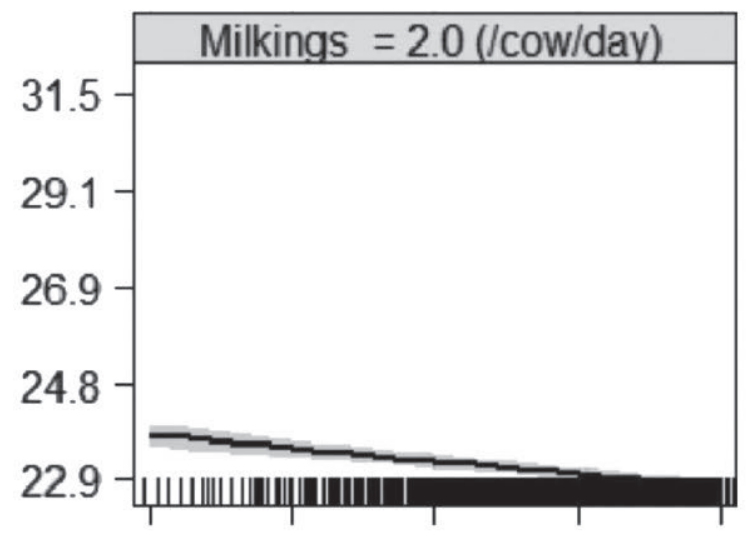

$\begin{array}{lllll}14.1 & 21.4 & 32.5 & 49.4 & 75.0\end{array}$

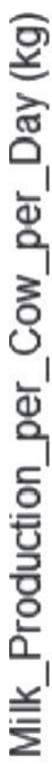

b)

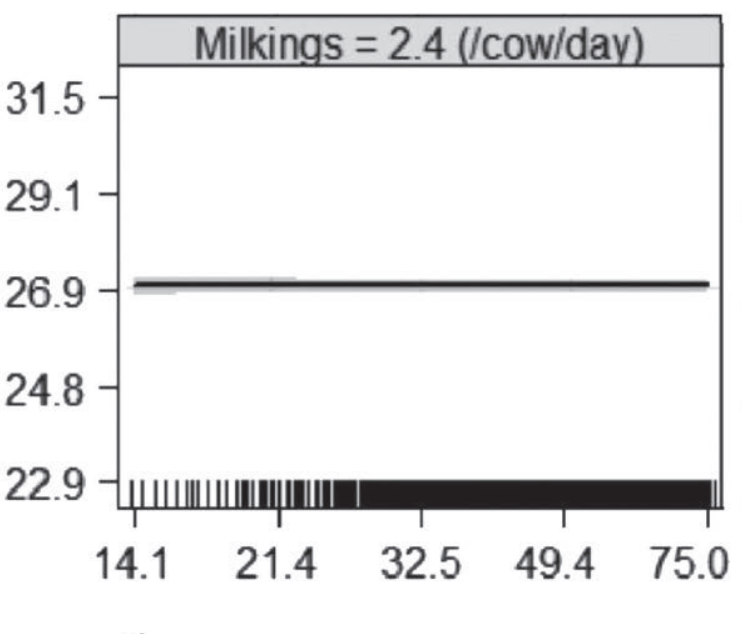

c)

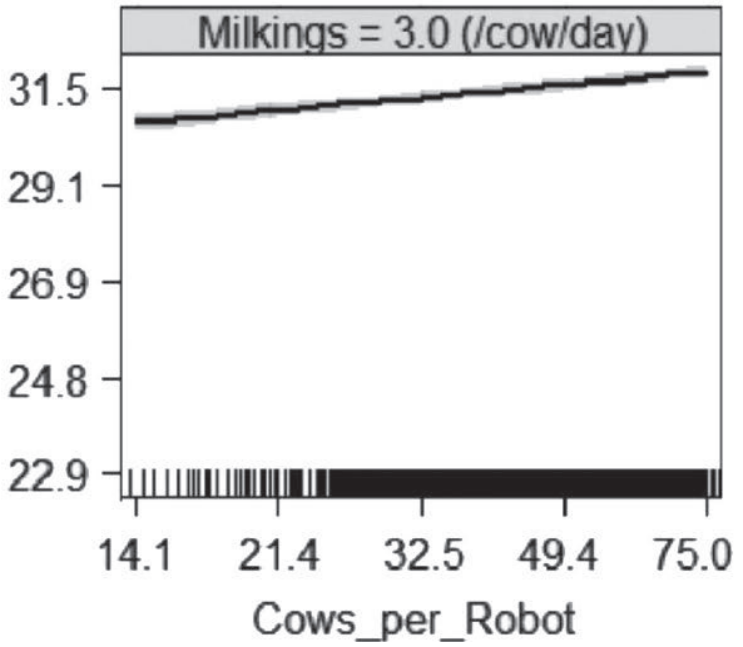

Figure 4. Interaction effects between predictor variables Cows_ per_Robot and Milkings with Milk_Production_per_Cow_per_Day as the response variable. Tick marks on the $\mathrm{x}$-axis represent individual measurements. 


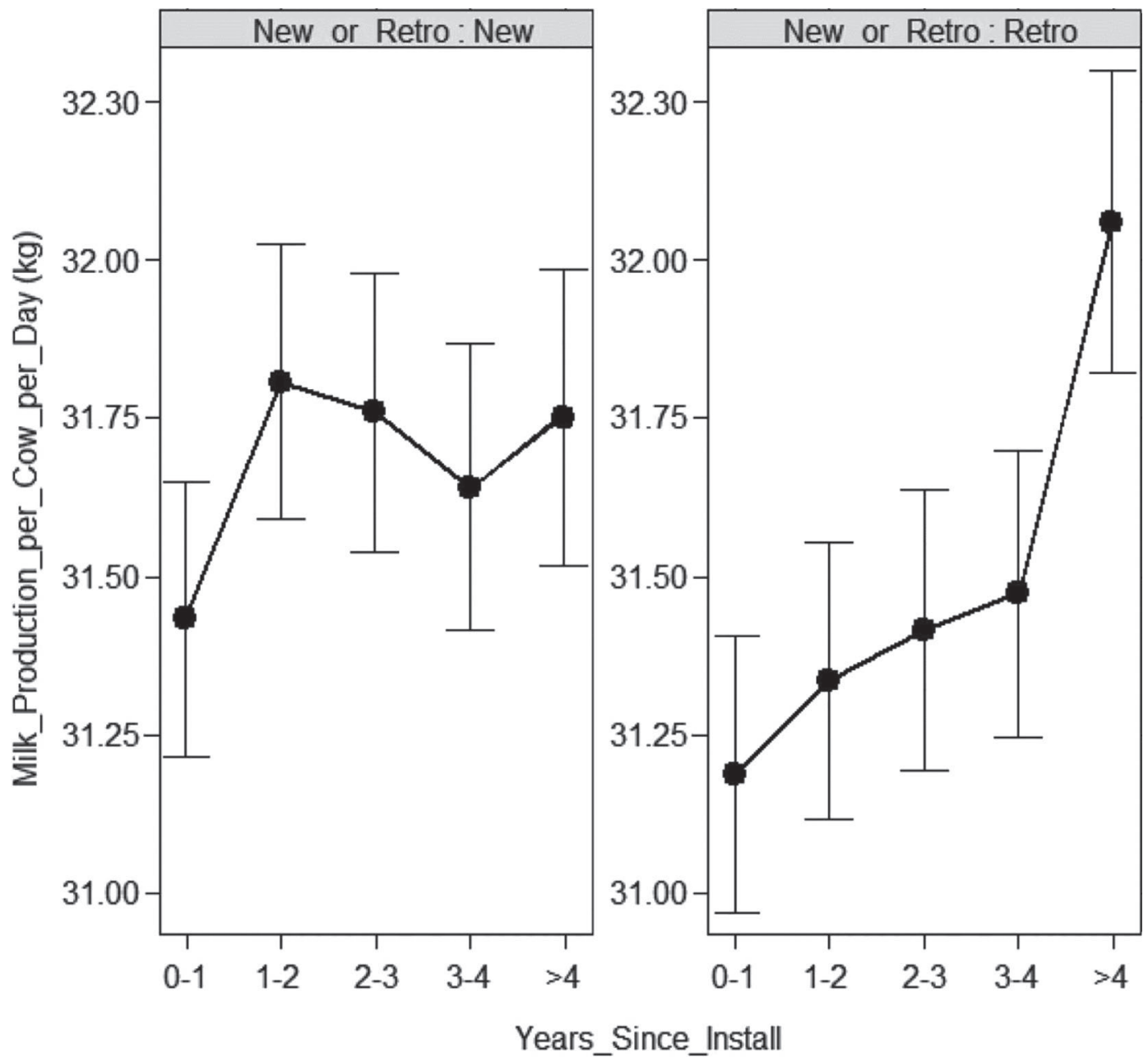

Figure 5. Interaction effects between predictor variables New_or_Retro and Years_Since_Install with Milk_Production_per_Cow_per_Day as the response variable. Error bars indicate 95\% confidence intervals.

AMS per cow in forced compared with free traffic type. Winter and Hillerton (1995) found that cows spent less time resting with forced traffic type although Munksgaard et al. (2011) did not find a significant difference in milking frequency, production, lying time, or feeding time between traffic type in a study with 70 cows.

Limited sample size has been a common problem in previous studies comparing traffic types. The largest sample size of any of the previous studies mentioned was 160 cows and most other studies included fewer than 100 cows. Furthermore, many of these studies did not correct for confounders and other risk factors in the applied modeling approaches. For example, Gygax et al. (2007) collected data on 160 cows from 2 different traffic type farms each with either Brown Swiss or Holstein cows. Although no significant difference between traffic types was found, the herds in the study were not matched by breed nor did the investigators correct for breed in their model. The majority of free traffic type herds (3/4 herds) were Brown Swiss herds, whereas 3 out of 4 forced traffic type herds were Holstein herds. Even though both Brown Swiss and Holstein breeds are high yielding, Holsteins still produce significantly more milk than Brown Swiss (De Marchi et al., 2008). Many studies also have low numbers of cows per robot or did not correct for differences in cows per robot among study groups. For example, the Munksgaard et al. (2011) study had only 35 cows per robot, and Gygax et al. (2007) did not correct for the variation in cows per robot in spite of a range from 30 to 56 cows per robot. Our study showed Cows_per_Robot had a significant effect on Milk_Production and was included in several significant interactions with other risk factors. The number of cows per robot could affect results because the hierarchic structure of the herd and its influence on timid cows is suspected to play a lesser 
role in small groups and to have a greater effect in large groups. This effect may further increase under normal farm circumstances with little Robot_Free_Time.

We found that Robots_per_Pen "2" was associated with greater Milk_Production_per_Robot_per_Day than Robots_per_Pen "1." Although this difference was not significant for all years (Figure 1), the trend is consistent. A possible cause for this difference is that Robots_per_Pen "2" allows timid cows to have more opportunities for milking if dominant cows monopolize one of the robots. Timid cows have been shown to wait longer to use the robot than higher-ranking cows (Ketelaar-de Lauwere et al., 1996; Thune et al., 2002; Melin et al., 2006). Another benefit of having more than one robot per pen is that down time due to daily maintenance of a robot does not necessarily disrupt behavior because cows can still be milked in the other robot (Rodenburg, 2004). In addition, the effect of Robots_per_Pen could be representing the effect of the physical dimensions of the pens or the total group size, although these distinctions cannot be made based on this data set. Having 2 robots per pen will not be feasible for all farms especially those with low numbers of cows. As this is the first study examining the difference in number of robots per pen, subsequent studies are needed to understand the effects of pen dimensions and group size. It is important to consider additional arguments for or against increased Robots_per_Pen, which may reflect labor requirement, animal well-being and health, cow handling, as well as economics.

We found that increases in Boxtime and Milkings are associated with increased Milk_Production, but Boxtime and Milkings rarely increase simultaneously. As Cows_per_Robot increases, the Milkings will decrease and Boxtime will increase. Including interactions in the models allowed us to examine how cows with high Milk_Speed can help manage the conflicting goals of max production and cost efficiency. Cows with high Milk_Speed can be in a pen with greater Cows_per_ Robot without negatively affecting production because cows with high Milk_Speed spend less time in the AMS and require fewer Milkings, while concurrently maintain greater production than cows with average Milk_Speed, Milkings, and Boxtime (Tables 3 and 4). Therefore, selection for faster Milk_Speed may balance milk production with efficiency and a farm's ability to increase their Cows_per_Robot will depend on the average Milk_Speed of their herd.

We found that an increase in Concentrates is associated with decreased Milk_Production. This association most likely reflects environments that do not support the production of high-quality feed such as corn silage. The use of low-energy basic forages in the feed bunk ration increases the amount of concentrate that needs to be supplemented in the robot. Farms that must feed high volumes of concentrate in their robots due to their geographic circumstance experience greater reductions in productivity due to increases in refusals or connection attempts (Figure 2). Another possible cause of the effect of Concentrates on Milk_Production may be the variation in milk yield among cows in the herd. A herd with high milk yield and low variation can successfully lessen the volume of concentrate fed in the AMS and maintain the robot attractiveness for the majority of the cows. A herd with a greater variation in milk production may require a higher volume of Concentrates to keep the low-yielding cows attracted to the robot.

Although it is suggested to maintain the refusals above 1 per cow per day (Kozlowska et al., 2013), the negative effect of refusals on Milk_Production should not be overlooked. Stefanowska et al. (2000) found refusals negatively affected behavior because cows went through fewer complete behavioral cycles (eating and lying down) after nonmilking visits (refusals) versus after milking visits. The number of refusals per cow per day is not a very good indication of overcrowding. Not only was the interaction Refusals:Cows_per_Robot not selected in the forward selection process, but refusals can be a positive sign of cows' interest and curiosity in coming to the robot. Therefore, we suggest using the relationships between boxtime, milk speed, and number of milkings to develop overcrowding standards (Figure 3 and 4). This strategy could complement the evaluation of overcrowding based on number of refusals alone.

To our knowledge, this is the first attempt to assess the differences in the use of AMS between new and existing farms. We found that both scenarios can result in high milk production per cow or per robot, only that the "Retro" fitted farm need about 2 yr to reach the production levels of a "New" barn. Also, "Retro" fitted farms have significantly greater production in " $>4 \mathrm{yr}$ " Years_Since_Install compared with all other categories of Years_Since_Install (Figure 5). The difference in "New" and "Retro" fitted barns might reflect differences in the average lactation numbers of the cows. When new barns are constructed, a sharp increase in herd size often occurs consisting of many replacement heifers that are introduced to the robots during their first lactation. Retrofitted barns often must adapt older cows to the robot after those cows were previously trained for in-parlor milking. Heifers have been shown to learn to use the AMS quicker than cows (Jago and Kerrisk, 2011). The population of cows that were originally trained on robots as heifers will slowly increase in relative numbers over the years on retro farms. In addition, retrofitted farms also reflect a more gradual genetic 
improvement in the herd through culling and replacement rather than a sudden expansion. These factors may explain why the "Retro" fitted barns, unlike the "New" barns, have a significantly greater production in "> 4 yr" Years_Since_Install compared with all other categories of Years_Since_Install.

The main effects of Robot_Free_Time are contrary to what would be expected. The low number of observations with greater than 15\% Robot_Free_Time in 2011 and 2012 increases the uncertainty of the estimates and the data only represent relatively few farms, which increases the chance of a single farm creating bias in the estimates. Therefore, the years 2013 and 2014 should be examined as a more reliable representation of the differences among the Robot_Free_Time levels compared with 2011 and 2012. A likely reason for Milk_Production_per_Robot_per_Day increasing with greater Robot_Free_Time is the existence of an unknown confounder not included in the model. One such confounding effect might be automatic cleaning time. Farms trying to increase total production might decrease the number of times the system is cleaned to increase the time the robot is available for milking cows. Therefore, the robot is available more time per day to milk cows, but it still maintains a greater Robot_Free_Time. Another possible confounder is treatment time (time it takes the robot to clean, prep the udder, and postdip). Because Boxtime is made up of both milking time and treatment time, it is possible to maintain the same Boxtime and Milk_Speed by decreasing treatment time which yields longer milking time and more production. This is an example for a hypothesis-generating relationship that could be evaluated further in the future.

Although the 2 models included an extensive number of risk factors, they did not include every possible cause for variation, confounder, or type of farms. In addition to treatment time and cleaning time, variables such as lactation, milk components, herd size, cow health, robot model, nutrition, and other facility factors such as flooring, stall size, bedding, and ventilation were not part of the available data. The number of cows fetched into the AMS and cost efficiency were not included in the analysis, but could affect a farmer's decision between the 2 traffic systems, although the gain in milk per cow per day in free traffic type is potentially a substantial contributor to profit. Random effect of Farm_ID accounts for some differences between these unknown factors including the level of genetic value in herds. Grazing and organic herds were not included as their analysis might require different risk factors examined compared with the current cohort of farms. Including additional interactions in the model would most likely improve the model fit, but would also make interpretation more difficult.

The current study, looking at differences in milk production across farms utilizing AMS, has benefitted from a large sample of farms in diverse locations applying very different management strategies, breeds, and additional associated risk factors. The resulting associations are relatively robust and should contribute to the benchmarking processes in the industry. The results could be used to advise the benchmarks regarding AMS farms, a subject that has not been fully addressed in literature where benchmarks are generated across AMS and conventional milking technology on farms alike. It remains to be seen whether AMS farms need their own set of benchmarks and decision support structures, because of their specialized production systems. The analysis of large cohorts of AMS farms for the association of risk factors with milk production is a step in the right direction of customizing advice for AMS farms based on their individual management characteristics that could cluster them into distinct groups.

\section{ACKNOWLEDGMENTS}

We thank Lely North America (Pella, IA) for their financial support of this study. We gratefully acknowledge the editing effort of Nick Robl and the expertise of Rik van der Tol (Lely Industries N.V., Maassluis, the Netherlands) for his assistance in the planning of this project.

\section{REFERENCES}

Bach, A., M. Devant, C. Igleasias, and A. Ferrer. 2009. Forced traffic in automatic milking systems effectively reduces the need to get cows, but alters eating behavior and does not improve milk yield of dairy cattle. J. Dairy Sci. 92:1272-1280. http://dx.doi. org/10.3168/jds.2008-1443.

De Marchi, M., G. Bittante, R. Dal Zotto, C. Dalvit, and M. Cassandro. 2008. Effect of Holstein Friesian and Brown Swiss breeds on quality of milk and cheese. J. Dairy Sci. 91:4092-4102. http:// dx.doi.org/10.3168/jds.2007-0788.

Dormann, C. F., J. Elith, S. Bacher, C. Buchmann, G. Carl, G. Carré, J. R. García Marquéz, B. Gruber, B. Lafourcade, P. J. Leitão, T. Münkemüller, C. McClean, P. E. Osborne, B. Reineking, B. Schröder, A. K. Skidmore, D. Zurell, and S. Lautenbach. 2013. Collinearity: A review of methods to deal with it and a simulation study evaluating their performance. Ecography 36:27-46. http:// dx.doi.org/10.1111/j.1600-0587.2012.07348.x.

Fox, J. 2003. Effect displays in R for generalised linear models. J. Stat. Softw. 8:1-27. http://www.jstatsoft.org/v08/i15/.

Grant, R. J., and J. L. Albright. 2001. Effect of animal grouping on feeding behavior and intake of dairy cattle. J. Dairy Sci. 84(E-Suppl.):E156-163. http://dx.doi.org/10.3168/jds.S00220302(01)70210-X.

Greenland, S. 1989. Modeling and variable selection in epidemiologic analysis. Am. J. Public Health 79:340-349.

Gygax, L., I. Neuffer, C. Kaufmann, R. Hauser, and B. Wechsler. 2007. Comparison of functional aspects in two automatic milking sys- 
tems and auto-tandem milking parlors. J. Dairy Sci. 90:4265-4274. http://dx.doi.org/10.3168/jds.2007-0126.

Harms, J., G. Wendl, and H. Schön. 2002. Influence of cow traffic on milking and animal behaviour in a robotic milking system. Pages II8-II14 in First North Am. Conf. Robotic Milking. J. McLean, M. Sinclair, and B. West, ed. Wageningen Press, Wageningen, the Netherlands.

Hermans, G. G. N., A. H. Ipema, J. Stefanowska, and J. H. M. Metz. 2003. The effect of two traffic situations on the behavior and performance of cows in an automatic milking system. J. Dairy Sci. 86:1997-2004.

Jacobs, J. A., and J. M. Siegford. 2012. Invited review: The impact of automatic milking systems on dairy cow management, behavior, health, and welfare. J. Dairy Sci. 95:2227-2247. http://dx.doi. org/10.3168/jds.2011-4943.

Jago, J., and K. Kerrisk. 2011. Training methods for introducing cows to a pasture-based automatic milking system. Appl. Anim. Behav. Sci. 131:79-85. http://dx.doi.org/10.1016/j.applanim.2011.02.002.

Ketelaar-de Lauwere, C. C., S. Devir, and J. H. M. Metz. 1996. The influence of social hierarchy on the time budget of cows and their visits to an automatic milking system. Appl. Anim. Behav. Sci. 49:199-211. S0168-1591(96)01030-1.

Ketelaar-de Lauwere, C. C., M. M. W. B. Hendriks, J. Zondag, A. H. Ipema, J. H. M. Metz, and J. P. T. M. Noordhuizen. 2000. Influence of routing treatments on cows' visits to an automatic milking system, their time budget and other behaviour. Acta Agric. Scand. Anim. Sci. 50:174-183.

Kozlowska, H., A. Sawa, and W. Neja. 2013. Analysis of the number of cow visits to the milking robot. Acta Scientiarum Polonorum Zootechnica 12:37-47.

Melin, M., G. G. N. Hermans, G. Pettersson, and H. Wiktorsson. 2006. Cow traffic in relation to social rank and motivation of cows in an automatic milking system with control gates and an open waiting area. Appl. Anim. Behav. Sci. 96:201-214.

Melin, M., G. Pettersson, K. Svennersten-Sjaunja, and H. Wiktorsson. 2007. The effects of restricted feed access and social rank on feeding behavior, ruminating and intake for cows managed in automated milking systems. Appl. Anim. Behav. Sci. 107:13-21. http://dx.doi.org/10.1016/j.applanim.2006.09.026.

Munksgaard, L., J. Rushen, A. M. de Passillé, and C. C. Krohn. 2011. Forced versus free traffic in an automated milking system. Livest. Sci. 138:244-250. http://dx.doi.org/10.1016/j.livsci.2010.012.023.
Pasta, D. J. 2011. Those confounded interactions: Building and interpreting a model with many potential confounders and interactions. Paper 347-2011 in Proc. SAS Global Forum 2011. SAS Inst. Inc., Cary, NC

Quinn, G. P., and M. J. Keough. 2002. Experimental Design and Data Analysis for Biologists. Cambridge University Press, Cambridge, UK.

R Development Core Team. 2013. R: A Language and Environment for Statistical Computing. R Foundation for Statistical Computing, Vienna, Austria. http://www.R-project.org/.

Rodenburg, J. 2002. Robotic milkers: What, where . . . and how much!!?? Pages 1-18 in Proc. Ohio Dairy Management Conf., Columbus, OH. Ohio State University Extension, Columbus.

Rodenburg, J. 2004. Housing considerations for robotic milking. ASAE Paper No. 044189, American Society of Agricultural and Biological Engineers, St Joseph, MI.

Rodenburg, J. 2012. The impact of robotic milking on milk quality, cow comfort and labor issues. Pages 126-137 in Natl. Mastitis Counc. Annu. Meet. Proc. St. Pete Beach, FL, Natl. Mastitis Counc., Madison, WI.

Stefanowska, J., M. Plavsic, A. H. Ipema, and M. M. W. B. Hendriks. 2000. The effect of omitted milking on the behaviour of cows in the context of cluster attachment failure during automatic milking. Appl. Anim. Behav. Sci. 67:277-291. http://dx.doi.org/10.1016/ S0168-1591(00)00087-3.

Telezhenko, E., M. A. G. von Keyserlingk, A. Talebi, and D. M. Weary. 2012. Effect of pen size, group size, and stocking density on activity in freestall-housed dairy cows. J. Dairy Sci. 95:3064-3069. http://dx.doi.org/10.3168/jds.2011-4953.

Thune, R. Ø., A. M. Berggren, L. Gravås, and H. Wiktorsson. 2002 Barn layout and cow traffic to optimize the capacity of an automatic milking system. Pages 45-50 in Proc. 1st North Am. Conf. Robotic Milking, Toronto, Canada. J. McLean, M. Sinclair, and B. West, ed. Wageningen Pers, Wageningen, the Netherlands.

Winter, A., and J. E. Hillerton. 1995. Behaviour associated with feeding and milking of early lactation cows housed in an experimental automatic milking system. Appl. Anim. Behav. Sci. 46:1-15. 